\title{
CRISES CAMBIAIS E ATAQUES ESPECULATIVOS NO BRASIL*
}

\author{
Mauro Costa Miranda ${ }^{\S}$
}

\begin{abstract}
RESUMO
O objetivo do estudo é investigar a hipótese de que fundamentos macroeconômicos explicam, em alguma medida, a ocorrência de crises cambiais e ataques especulativos no Brasil. Uma adaptação de um dos principais modelos de primeira geração de crise cambial foi utilizada como referencial teórico, produzindo uma equação de probabilidade de ocorrência de ataques especulativos em função de variáveis macroeconômicas. Instrumental econométrico foi utilizado para estimar os parâmetros dessa equação para o caso brasileiro. Os resultados obtidos são compatíveis com as hipóteses do modelo. As principais variáveis explicativas identificadas foram a oferta de moeda nacional, a taxa internacional de juros, taxa de câmbio de venda fixada pelo governo e a liberalização dos controles sobre o fluxo de capitais. As equações de probabilidade de ocorrência de crises cambiais e ataques especulativos estimadas demonstraram ser úteis para a previsão da iminência desses eventos.
\end{abstract}

Palavras-chave: política monetária, finanças internacionais, crise.

\begin{abstract}
The main goal of this paper is to investigate the hypothesis that currency crisis models based on macroeconomic fundamentals explain, to some extent, the occurrence of speculative attacks and currency crisis in Brazil. An adaptation of one of the main first generation models of currency crisis was used as theoretical background, producing an equation of the probability of occurrence of speculative attacks as function of macroeconomic variables. As an empirical application for the case of Brazil, an econometric model was utilized to estimate the parameters of this equation. The results were compatible with the hypothesis of the model. The most relevant variables identified were the monetary suply, the international interest rate, the exchange rate fixed by the government, and the liberalization of capital controls. The estimated equations for the probability of occurrence of currency crises and speculative attacks showed its usefulness to predict the imminence of these events.
\end{abstract}

Key words: monetary policy, international finance, crisis.

JEL classification: E52, F32, F34, F37.

\footnotetext{
* O texto foi publicado como Working Paper $n^{\circ} 32$ do Banco Central do Brasil. As opiniões expostas não necessariamente representam a visão dessa instituição. Agradeço os comentários de um parecerista. Erros remanescentes são de minha exclusiva responsabilidade.

$\S \quad$ Universidade de Brasília (UnB). Endereço para contato: Universidade de Brasília - FACE - Dep. de Economia - Módulo de Pós-Graduação - Brasília (DF) - CEP 70.910-900.E-mail: curupira@unb.br.

Recebido em setembro de 2004. Aceito em agosto de 2005.
} 


\section{INTRODUÇÃO}

A investigação dos principais fatores determinantes da ocorrência de ataques especulativos e crises cambiais é uma questão aberta a extenso debate, produzindo literatura em rápida ampliação. Os assim chamados modelos de primeira geração explicavam as crises cambiais como decorrência do crescimento do crédito interno líquido, principalmente para o financiamento do déficit público, sob regime de câmbio fixo e dadas as reservas internacionais limitadas. Os modelos de segunda geração introduziram questões tais como equilíbrio múltiplo e ataques especulativos auto-realizáveis, contágio e fragilidade financeira. Esta segunda geração multiplicou-se com mais rapidez a partir dos anos noventa, motivada pelas evidências proporcionadas pelas crises cambiais no arranjo cambial europeu, no México e nos países asiáticos. Como exporemos adiante, alguns estudos recentes têm explorado a complementaridade das teorias de primeira e de segunda gerações.

A economia brasileira esteve sujeita a vários episódios de ataques especulativos e crises cambiais nos anos oitenta e noventa. Andrade e Divino (1999) estudaram a variação das reservas internacionais em função de fundamentos macroeconômicos selecionados e de uma proxy para o contágio. Outros estudos focalizaram eventos específicos, como a crise da dívida externa (Fritsch, 1985), o ataque especulativo de 1997 (Aurélio e da Silva, 1999) e a crise cambial de 1999 (Goldfajn, 2000).

O propósito deste trabalho é realizar um exercício exploratório de identificação dos fundamentos macroeconômicos determinantes de ataques especulativos e crises cambiais no Brasil, considerando-se as décadas de oitenta e noventa. A importância de circunstâncias de equilíbrio múltiplo, contágio e vulnerabilidade financeira não é ignorada; ao contrário, é destacada na identificação das crises cambiais. Entretanto, dada a multiplicidade de hipóteses a serem testadas, reservamos essa abordagem ao exame específico e pormenorizado de cada episódio de ataque especulativo ou crise cambial a ser efetuado em estudos subseqüentes. Mais precisamente, o objetivo deste estudo é a estimação dos parâmetros da equação de probabilidade de ocorrência de crises cambiais e ataques especulativos no Brasil em função de variáveis macroeconômicas selecionadas, referidas no modelo proposto por Ötker e Pazarbasioglu (1995), utilizando método estatístico já consolidado por seu retrospecto empírico. A hipótese é que esses fatores explicam, em alguma medida, a ocorrência de crises cambiais e ataques especulativos no Brasil.

O texto está organizado da seguinte forma. Na seção 2 é realizado o exame genérico da literatura teórica sobre crises cambiais e ataques especulativos. Na seção 3 é descrito o modelo de Ötker e Pazarbasioglu (1995). Na seção 4 são estimados os parâmetros da equação de probabilidade de ocorrência de crises cambiais e ataques especulativos no caso brasileiro. Finalmente, na seção 5 são apresentados os comentários finais.

\section{APRESENTAÇÃO DA LITERATURA BÁSICA}

A teoria econômica a respeito de ataques especulativos e crises cambiais tem observado expansão acelerada. Pelo menos quatro hipóteses de fatores causais preponderantes podem ser identificadas na literatura: (a) fundamentos macroeconômicos; (b) equilíbrio múltiplo; (c) contágio; (d) vulnerabilidade financeira. Por vezes, essas hipóteses são competidoras; por vezes, são complementares, embora a literatura mais recente caminhe no sentido da complementaridade de explicações. (Pesenti e Tille, 2000). 
Modelos de crises cambiais baseados em fundamentos macroeconômicos, conhecidos por modelos de primeira geração, originaram-se a partir do artigo de Krugman (1979). O autor apresenta um modelo no qual o déficit fiscal é financiado por emissão de moeda que, sob regime de câmbio fixo, implica redução das reservas internacionais. Agentes privados, nacionais e estrangeiros, prevendo o esgotamento dessas reservas e a subseqüente desvalorização da taxa de câmbio, trocam moeda nacional por moeda estrangeira e precipitam o fim do regime de câmbio fixo. Esse modelo foi acrescido de uma grande variedade de complementos e sofisticações, sobre as quais Garber e Svensson (1995) e Agénor et alii (1992) são resenhas úteis.

Flood e Garber (1984), em particular, tornaram o modelo de Krugman (1979) linear e estocástico por meio da inclusão de emissão monetária constante, sujeita a erro aleatório. Essa transformação permitiu aos autores derivar uma equação de probabilidade de ocorrência de crises cambiais e ataques especulativos que deu ensejo à realização de inúmeros estudos de caráter empírico. Kaminsky et alii (1998) é o exemplo mais notável, tendo revisado outros 25 estudos cuja característica comum era a identificação de variáveis macroeconômicas que explicariam a ocorrência de crises cambiais e ataques especulativos. Seus resultados demonstraram que as exportações, a taxa real de câmbio e a razão entre reservas internacionais e meios de pagamento estão entre os melhores indicadores da iminência de crises cambiais, oferecendo respaldo aos modelos de primeira geração.

Os acontecimentos que envolveram o fim da serpente cambial européia, particularmente as desvalorizações da libra esterlina e da coroa sueca, deslocaram o foco da questão. Os modelos teóricos de crises cambiais até então postulados não pareciam suficientes para a explicação dessas desvalorizações. Quaisquer dos países atingidos teriam plenas condições de defender sua respectiva moeda tanto por deterem reservas internacionais suficientes para readquirir praticamente a totalidade da base monetária quanto por terem amplo acesso ao mercado financeiro, podendo emitir títulos externos com o fito de recuperar as reservas internacionais. Assim procedendo, entretanto, as taxas de juros elevar-se-iam a ponto de colocar em risco o sistema financeiro e prejudicar o crescimento do produto agregado. Dessa forma, a desvalorização cambial provocada pelo ataque especulativo é, em última instância, uma opção do governo pelo abandono da fixação do câmbio, priorizando outros objetivos de política econômica, notadamente a preservação do sistema financeiro e do emprego. (Obstfeld e Rogoff, 1995).

A possibilidade de equilíbrio múltiplo surge nessa circunstância, na qual os participantes do mercado, apesar de não questionarem a compatibilidade da política econômica de um país com a manutenção da taxa fixa de câmbio, antecipam que um ataque especulativo pode alterar a política econômica adotada. Existem dois equilíbrios possíveis para a economia: o primeiro é caracterizado pela ausência do ataque especulativo e pela manutenção da taxa fixa de câmbio; o segundo é caracterizado pelo ataque especulativo e pela mudança dos fundamentos macroeconômicos que justifica, a posteriori, a mudança cambial esperada pelos agentes (Eichengreen et alii, 1997). Nesse sentido, o ataque especulativo assume a característica de ser auto-realizável, ou seja, ele "realiza" uma desvalorização cambial que não ocorreria na sua ausência.

Modelos mais recentes reconciliam as teorias baseadas em fundamentos macroeconômicos com aquelas baseadas em equilíbrio múltiplo. Burnside et alii (2000), Cavallari e Corsetti (2000), Jeanne (1997) e Cole e Kehoe (1996) modelam circunstâncias nas quais fundamentos macroeconômicos e condições de equilíbrio múltiplo atuam complementarmente, tornando possível a ocorrência de ataques especulativos auto-realizáveis.

As crises cambiais nos países europeus, em 1992, e nos países asiáticos, em 1997, estimularam o surgimento das teorias baseadas no contágio. O contágio consiste na ocorrência de crises cambiais e ataques especulativos simultaneamente ou seqüencialmente em diversos países. Caramazza et alii 
(2000), Kaminsky e Reinhart (1999) e Eichengreen et alii (1997) oferecem revisões de modelos de crises cambiais baseados em contágio. Podemos supor cinco potenciais causas de contágio: (a) alterações de políticas macroeconômicas em economias centrais (tais como aumento da taxa de juros) que afetem simultaneamente muitas economias em desenvolvimento; (b) perda de competitividade de um país perante parceiros comerciais ou concorrentes em terceiros mercados; (c) falta de incentivos para obter informações específicas de cada país, considerando vários países aparentemente em circunstâncias semelhantes a outros atingidos por crise cambial (Calvo, 2000); (d) perda de credibilidade dos investidores internacionais na convicção do governo de um país de manter a paridade cambial quando outro país, em circunstância semelhante, optou pela desvalorização (Masson, 1998); e (e) realocações de ativos financeiros entre países para suprir necessidades de capital (Goldfajn e Valdés, 1997). Andrade e Divino (1999), examinando a economia brasileira no período de 1971 a 1998, verificaram a atuação significativa tanto de fundamentos macroeconômicos quanto de uma proxy de contágio enquanto fatores determinantes de crises cambiais e ataques especulativos.

As crises cambiais ocorridas nos países asiáticos no segundo semestre de 1997 não só reforçaram as teorias baseadas em contágio, mas trouxeram ao debate a relação entre as fragilidades dos sistemas financeiros de cada país e a ocorrência de crises cambiais. Chang e Velasco (1998) argumentam que a fragilidade do sistema financeiro de diversos países asiáticos consistiu na concessão excessiva de crédito de médio prazo e de longo prazo ao setor privado alavancado por débitos de curto prazo com o exterior. Em outras palavras, o sistema financeiro mantinha um ativo de curto prazo muito inferior ao passivo de curto prazo em moeda estrangeira. No momento em que os credores estrangeiros decidiram resgatar seus investimentos, os bancos asiáticos recorreram aos respectivos bancos centrais, na condição de emprestadores de última instância e de mantenedores da taxa de câmbio. Estes, por sua vez, viram-se incapazes de prover recursos suficientes para respaldar as saídas de capitais estrangeiros, daí decorrendo a crise cambial.

\section{O MODELO UTILIZADO}

Foi escolhido o modelo de Ötker e Pazarbasioglu (1995) - doravante designado por OP - porque ele produz, explicitamente, uma equação de probabilidade de ocorrência de crises cambiais e ataques especulativos em função dos fundamentos macroeconômicos. Adicionalmente, essa equação foi objeto de extensa investigação empírica, estabelecendo, assim, um método econométrico de estimação já consolidado. O modelo demonstrou bom desempenho explicativo, mensurado pelo coeficiente de determinação, quando aplicado à experiência mexicana no período de 1982 a 1994.

O modelo é concebido para uma economia pequena e aberta, valendo a paridade do poder de compra e a paridade não-coberta da taxa de juros. Admite-se que os ativos disponíveis aos residentes sejam a moeda nacional, os títulos nacionais, a moeda estrangeira e os títulos estrangeiros. $\mathrm{O}$ governo utiliza um estoque de reservas internacionais para determinar a taxa de câmbio. A moeda nacional é preferida à estrangeira por esta não oferecer nenhum serviço monetário aos residentes. As equações estruturais do modelo OP são as seguintes:

$$
\begin{aligned}
& \mathrm{m}^{\mathrm{d}}-\mathrm{p}=\mathrm{a}_{0}+\Omega y-\mathrm{a}_{1} \cdot \mathrm{i}+\omega \\
& \mathrm{m}^{\mathrm{o}}=\log (\mathrm{D}+\mathrm{R}) \\
& \mathrm{i}=\mathrm{i}^{*}+\mathrm{E}\left[\Delta \mathrm{e}_{+1}\right]
\end{aligned}
$$




$$
\begin{aligned}
& \mathrm{p}=\mathrm{p}^{*}+\mathrm{e}-\mathrm{er} \\
& \mathrm{m}^{\mathrm{d}}=\mathrm{m}^{\mathrm{o}}
\end{aligned}
$$

onde $\mathbf{m}, \mathbf{p}$ e y são os logaritmos do estoque de moeda, do nível interno de preços e do produto real, respectivamente, i é a taxa de juros interna nominal, $\omega$ é um erro aleatório de média zero da demanda por moeda, $\mathbf{D}$ é o crédito interno líquido, $\mathbf{R}$ são as reservas internacionais, $\mathbf{i}^{*}$ é a taxa internacional de juros, $\mathrm{p}^{*}$ é o logaritmo do nível internacional de preços e, finalmente, e e er são os logaritmos da taxa de câmbio e da taxa real de câmbio, respectivamente. A taxa de câmbio é definida em unidades de moeda nacional requeridas para comprar uma unidade da moeda estrangeira. Aumento da taxa de câmbio representa desvalorização da moeda nacional. Similarmente, o aumento da taxa real de câmbio implica desvalorização real da moeda. Os sobrescritos d e o representam demanda e oferta e $\mathrm{a}_{0}$ e $\mathrm{a}_{1}$ são parâmetros constantes. $\mathrm{O}$ operador $\Delta$ indica a primeira diferença.

A equação (1) especifica a demanda por moeda motivada por razões de liquidez e de investimento. A equação (2) define crédito interno como a diferença entre a oferta monetária e as reservas internacionais avaliadas em moeda nacional. A equação (3) é a paridade não-coberta da taxa de juros, especificando que a taxa de juros interna é equivalente à externa acrescida da desvalorização cambial esperada. A equação (4) permite desvios da paridade do poder de compra pela introdução da taxa real de câmbio. A equação (5) determina o equilíbrio no mercado monetário.

O equilíbrio entre oferta e demanda de moeda determina o nível de reservas internacionais, se o câmbio é fixo (ef), ou a taxa de câmbio, se vigorar regime de câmbio livre. Quando as reservas se exaurem ou atingem um nível crítico Rc, o governo é obrigado a desvalorizar a taxa de câmbio ou permitir sua flutuação. A taxa de câmbio sombra e' é aquela que proporcionará equilíbrio ao mercado monetário no caso de crise cambial, podendo ser obtida a partir das equações estruturais. Igualando as equações (1) e (2) conforme (5), obtemos:

$$
\mathrm{p}+\mathrm{a}_{0}+\Omega \mathrm{y}-\mathrm{a}_{1} \cdot \mathrm{i}+\omega=\log (\mathrm{D}+\mathrm{Rc})
$$

onde Rc é o estoque de reservas internacionais preservadas após o ataque especulativo. A taxa interna de juros i e o nível interno de preços p podem ser substituídos, na equação (6), por seus valores dados nas equações (3) e (4), de forma a obtermos:

$$
\mathrm{p}^{*}+\mathrm{e}^{\prime}-\mathrm{er}+\mathrm{a}_{0}+\Omega \mathrm{y}-\mathrm{a}_{1} \cdot\left\{\mathrm{i}^{*}+\mathrm{E}\left[\Delta \mathrm{e}_{+1}\right]\right\}+\omega=\log (\mathrm{D}+\mathrm{Rc})
$$

Podemos, então, isolar o termo e' $-\mathrm{a}_{1} \cdot \mathrm{E}\left[\mathrm{e}_{+1}{ }_{+1}\right]$ ao lado esquerdo da equação:

$$
\begin{aligned}
& \mathrm{e}^{\prime}-\mathrm{a}_{1} \cdot E\left[\Delta \mathrm{e}^{\prime}{ }_{+1}\right]=\log (\mathrm{D}+\mathrm{Rc})-\mathrm{p}^{*}+\mathrm{er}-\mathrm{a}_{0}-\Omega \mathrm{y}+\mathrm{a}_{1} \cdot \mathrm{i}^{*}-\omega \\
& \left(1+\mathrm{a}_{1}\right) \cdot \mathrm{e}^{\prime}-\mathrm{a}_{1} \cdot \mathrm{E}\left[\mathrm{e}^{\prime}{ }_{+1}\right]=\log (\mathrm{D}+\mathrm{Rc})-\mathrm{p}^{*}+\mathrm{er}-\mathrm{a}_{0}-\Omega \mathrm{y}+\mathrm{a}_{1} \cdot \mathrm{i}^{*}-\omega
\end{aligned}
$$

Assumindo que os fundamentos macroeconômicos da equação (7) seguem um processo regressivo de primeira ordem e usando o método dos coeficientes indeterminados, essa equação pode ser solucionada para a taxa de câmbio sombra como uma função não-linear dos fundamentos. Assim, podemos escrever: 


$$
\mathrm{e}^{\prime}{ }_{+1}=\mathrm{f}\left(\log (\mathrm{D}+\mathrm{Rc})-\mathrm{p}^{*}+\mathrm{er}-\mathrm{a}_{0}-\Omega \mathrm{y}+\mathrm{a}_{1} . \mathrm{i}^{*}-\omega\right)
$$

A crise cambial ocorre quando a taxa de câmbio que vigorar após o esgotamento das reservas internacionais for superior à taxa de câmbio previamente fixada pelo governo. Os agentes privados participam do ataque especulativo na expectativa de comprarem moeda estrangeira pelo preço ef e venderem-na pelo preço e', auferindo lucro da diferença. Obviamente, esse lucro só existirá se e'> ef. Assim, a probabilidade $\pi$ de uma mudança de regime no momento $\mathrm{t}+1$ é equivalente à probabilidade de que a taxa de câmbio sombra no momento $t+1, \mathrm{e}_{+1}$ exceda a taxa de câmbio fixa ef. Daí, ser esta probabilidade função da taxa de câmbio sombra esperada para o momento t+1 e da taxa de câmbio fixa ef, ou seja:

$$
\pi=\operatorname{Pr}\left[e^{\prime}{ }_{+1}>e f\right]=\operatorname{Pr}\left[f\left(\log (D+R c)-p^{*}+e r-a_{0}-\Omega y+a_{1} \cdot i^{*}-\omega\right)>e f\right]
$$

Essa equação é utilizada para a estimação da probabilidade de ocorrência de um ataque especulativo ou crise cambial no momento $t+1$ em função de fundamentos macroeconômicos no momento t.

\section{EXERCÍCIO ECONOMÉTRICO E RESULTADOS}

Nesta seção são analisadas duas questões: (a) o poder de explicação do modelo OP quanto à ocorrência de ataques especulativos e crises cambiais no Brasil; (b) qual a probabilidade estimada de ocorrência de crises cambiais e ataques especulativos no Brasil para o período examinado, segundo o modelo.

Os parâmetros da equação de probabilidade de ocorrência de crises cambiais e de ataques especulativos - equação 9 - foram estimados. O método Probit foi escolhido em decorrência do caráter binomial da variável dependente $\pi$. A variável dependente assume valor um se ocorreu crise cambial ou ataque especulativo ou zero no caso contrário. As variáveis explicativas são os fundamentos macroeconômicos constantes no lado direito dessa equação. A probabilidade de ocorrência de crises cambiais e ataques especulativos foi calculada, para o período em exame, a partir dos parâmetros estimados nas regressões.

Os resultados das regressões efetuadas não permitem rejeitar a hipótese de que os ataques especulativos e crises cambiais ocorridos no Brasil entre janeiro de 1982 e janeiro de 1999 podem ser explicados pelos fundamentos macroeconômicos indicados no modelo OP.

O período amostral, de janeiro de 1982 a janeiro de 1999, compreende 205 observações (meses). Uma vez que as variáveis explicativas de um determinado mês dizem respeito à ocorrência de ataque especulativo ou crise cambial no mês seguinte, a amostra foi ajustada para 204 observações.

O modelo considerou o efeito do produto interno bruto e da taxa real de câmbio sobre a probabilidade de ocorrência de crises cambiais e ataques especulativos por meio da demanda por moeda nacional. Entretanto, é sabido que aquelas variáveis afetam o saldo do balanço comercial. No período em exame, observou-se correlação positiva entre o nível da taxa real efetiva de câmbio e o saldo da balança comercial $(70 \%)$ e, negativa, entre este e o produto interno bruto $(-73 \%)$.

As regressões foram efetuadas em duas diferentes versões. A primeira, considerando como regressores o conjunto de fundamentos macroeconômicos indicados pelo modelo OP. A segunda, acrescentando o saldo do balanço comercial ao conjunto de regressores da primeira versão. A inclusão do saldo do balanço comercial vai além do escopo do modelo adotado, porém permitimo-nos essa experimentação devido ao retrospecto empírico dessa variável, à sua ampla interação com o 
produto interno bruto e com a taxa real de câmbio e por ser ela indicada pelo modelo original de Krugman (1979).

\subsection{Identificação de crises cambiais e ataques especulativos}

A identificação de crises cambiais e de ataques especulativos na economia real é mais complexa do que a mera aplicação automatizada do conceito teórico. É possível dividir os critérios de identificação de ataques especulativos e de crises cambiais em critérios quantitativos e critérios qualitativos. Uma revisão ampla desses estudos empíricos é encontrada em Kaminsky et alii (1998).

No primeiro grupo, de critérios quantitativos, alguns autores estabeleceram limites numéricos para as variações da taxa de câmbio, da taxa real de câmbio, das reservas internacionais ou de um índice conjugando essas variáveis. Kaminsky et alii (1998) produziram um índice de pressão sobre o mercado cambial, definido como a média ponderada das variações mensais positivas da taxa nominal de câmbio e, negativas, das reservas internacionais. Uma crise cambial ocorre quando esse índice é superior à sua média por diferença superior a três desvios padrões. Goldfajn e Valdés (1997) estabeleceram três critérios de identificação: (a) uma desvalorização cambial maior que 1,96 vez o desvio padrão da taxa de desvalorização cambial nominal e $2 \%$ mais 1,5 vez a taxa de desvalorização no mês precedente; (b) uma desvalorização da taxa real de câmbio maior que a média por uma diferença superior a duas vezes o desvio padrão; (c) ataques especulativos previamente identificados por Kaminsky e Reinhart (1996). Frankel e Rose (1996) definiram crise cambial como a ocorrência de desvalorização nominal de $25 \%$ da taxa de câmbio, sendo também no mínimo $10 \%$ maior que a taxa de desvalorização do período anterior. Eichengreen et alii (1995) elaboraram um índice de ataque especulativo que pondera três fatores: a desvalorização cambial, a redução das reservas internacionais e a elevação abrupta das taxas de juros.

No segundo grupo, de critérios qualitativos, outros autores identificaram crises cambiais e ataques especulativos como desvalorizações discretas ou mudanças de regime cambial. Melick (1996), estudando o caso mexicano, definiu crise cambial como desvalorização acentuada (sem definir um limite mínimo) ou mudança para regime cambial mais flexível. A aceleração da desvalorização da taxa de câmbio foi considerada crise cambial. Ötker e Pazarbasioglu (1995), também estudando o caso mexicano, adotaram definição semelhante à de Melick (1996), embora se observe que, das nove crises cambiais apontadas por esses autores, apenas cinco corresponderam àquelas identificadas por Melick (1996) no mesmo período. Goldberg (1994) definiu um colapso cambial da mesma forma que Melick (1996) e Ötker e Pazarbasioglu (1995), apesar de não ter explicitado quais períodos foram efetivamente identificados como crises cambiais. Cumby e van Wijnbergen (1989) e Blanco e Garber (1986) também utilizaram como critério desvalorizações cambiais discretas e acentuadas e/ou mudanças de regimes cambiais.

O critério de identificação de ataques especulativos adotado foi composto por três identificadores: (a) desvalorização cambial discreta e acentuada; (b) grande perda de reservas internacionais; (c) mudança de regime cambial. Portanto, a exemplo de outros estudos de caso, não foram estabelecidos critérios quantitativos de identificação. Na recuperação da política cambial brasileira nas décadas de oitenta e noventa foi utilizada ampla literatura, mas Bonomo e Terra (1999) oferecem uma síntese útil, bem como os relatórios anuais do Banco Central do Brasil. Em Miranda (1999), apresenta-se com mais detalhe a tipificação dos ataques especulativos e crises cambiais ocorridos no Brasil. As variações da taxa de câmbio e das reservas internacionais nos períodos em que foram identificados ataques especulativos e crises cambiais são apresentadas na Tabela 1. 
Tabela 1 - Variação das reservas internacionais e da taxa de câmbio durante os meses em que foram identificados ataques especulativos e crises cambiais

\begin{tabular}{lccl}
\hline $\begin{array}{l}\text { Meses em que ocorreram } \\
\text { ataques especulativos ou } \\
\text { crises cambiais }\end{array}$ & $\begin{array}{c}\text { Variação das reservas } \\
\text { internacionais no mês (\%) }\end{array}$ & $\begin{array}{c}\text { Variação da taxa de câm- } \\
\text { bio no mês (\%) }\end{array}$ & Observação \\
\hline 1982: setembro & $-27,5$ & 7,0 & moratória do México \\
1982: outubro & $-23,2$ & 7,0 & \\
1983: janeiro & $-21,6$ & 8,9 & \\
1983: fevereiro & 2,3 & 38,6 & maxidesvalorização em 21.2.83 \\
1986: outubro & $-11,3$ & 1,8 & fim do câmbio fixo (Plano Cruzado) \\
1986: dezembro & $-8,0$ & 5,2 & \\
1987: janeiro & $-20,4$ & 10,7 & \\
1987: fevereiro & $-7,7$ & 19,7 & moratória \\
1989: abril & $-7,1$ & 3,2 & fim do câmbio fixo (Plano Verão) \\
1989: maio & $-11,2$ & 11,7 & \\
1989: junho & $-1,3$ & 31,7 & retorno das minidesvalorizações \\
1990: outubro & $-1,4$ & 27,0 & Plano Collor \\
1990: novembro & $-12,7$ & 35,3 & \\
1991: setembro & $-14,1$ & 18,1 & maxidesvalorização em 30.9.91 \\
1991: outubro & 0,4 & 38,7 & \\
1994: dezembro & $-7,5$ & 0,1 & crise cambial do México \\
1995: março & $-11,2$ & 5,2 & bandas de câmbio (Plano Real) \\
1997: outubro & $-13,3$ & 0,6 & crise cambial da Ásia \\
1998: setembro & $-32,0$ & 0,6 & crise cambial da Rússia \\
1999: janeiro & $-18,9$ & 65,0 & fim do Plano Real \\
\hline F & & &
\end{tabular}

Fonte: Bacen e elaboração própria.

\subsection{Variáveis, dados e fontes}

O período escolhido, de janeiro de 1982 a janeiro de 1999, inclui 205 meses (observações), tendo sido observadas 22 crises cambiais ou ataques especulativos. Todas as séries nominais foram deflacionadas pelo Índice Geral de Preços - Disponibilidade Interna (IGP-DI) da Fundação Getulio Vargas. Introduzimos uma variável adicional: o saldo da balança comercial, além de uma variável dummy, para avaliar a liberalização dos controles sobre os fluxos de capitais ao longo do período. As variáveis macroeconômicas indicadas pelo modelo OP, as fontes de coleta desses dados e os respectivos sinais esperados de seus parâmetros são apresentados na Tabela 2. 
Tabela 2 - Variáveis independentes, dados e fontes

\begin{tabular}{|c|c|c|c|}
\hline Conceito e símbolo & Variável utilizada & $\begin{array}{l}\text { Sinal esperado } \\
\text { do parâmetro }\end{array}$ & Observações \\
\hline Oferta de moeda (M) & $\begin{array}{l}\text { Meios de pagamento de liquidez } \\
\text { imediata (M1) ou acrescidos de títu- } \\
\text { los públicos federais (M2) }\end{array}$ & + & \\
\hline Reservas internacionais (R) & $\begin{array}{l}\text { Reservas internacionais, conceito } \\
\text { de liquidez }\end{array}$ & - & $\begin{array}{l}\text { Convertidas em moeda nacional pela } \\
\text { taxa de câmbio de venda }\end{array}$ \\
\hline Taxa internacional de juros (i*) & $\begin{array}{l}\text { Libor a prazo de seis meses e con- } \\
\text { tratos em US\$ }\end{array}$ & + & \\
\hline Nível externo de preços $\left(\mathrm{P}^{*}\right)$ & $\begin{array}{l}\text { Cesta de índices de preços no ata- } \\
\text { cado dos } 15 \text { principais parceiros } \\
\text { comerciais do Brasil }\end{array}$ & - & \\
\hline Taxa "fixa" de câmbio (EF) & $\begin{array}{l}\text { Taxa de câmbio de venda fixada pelo } \\
\text { Banco Central }\end{array}$ & - & $\begin{array}{l}\text { Taxa anunciada pelo Bacen de venda } \\
\text { em leilões públicos ou teto de banda } \\
\text { de câmbio }\end{array}$ \\
\hline Produto Interno Bruto $(Y)$ & Produto interno bruto real & - & $\begin{array}{l}\text { Interpolado para periodicidade mensal } \\
\text { e dessazonalizado }\end{array}$ \\
\hline Taxa real de câmbio (ER) & Taxa real efetiva de câmbio & - & $\begin{array}{l}\text { IPA-DI da FGV em relação às moedas } \\
\text { dos } 15 \text { principais parceiros comerciais } \\
\text { do Brasil }\end{array}$ \\
\hline Controle de fluxo de capitais (DLC) & Variável dummy & + & Criação do Anexo IV em maio de 1991 \\
\hline Balança comercial (TB) & Saldo da balança comercial & - & \\
\hline
\end{tabular}

Fonte: Banco Central do Brasil - Departamento Econômico.

\subsection{Resultados}

Os parâmetros estimados indicam que a probabilidade de ocorrência de ataques especulativos e de crises cambiais foi crescente em função da oferta de moeda nacional, da taxa real efetiva de câmbio, da taxa internacional de juros na forma direta e da variável dummy associada à liberalização dos controles sobre o fluxo de capitais, e decrescente em função das reservas internacionais, do produto interno bruto, da taxa de câmbio de venda fixada pelo governo, do quadrado da taxa internacional de juros, do nível externo de preços e do saldo da balança comercial (Tabela 3). Portanto, os sinais de todos os parâmetros estimados corresponderam aos previstos pelo modelo.

Na versão do modelo OP sem o saldo da balança comercial, a oferta de moeda nacional, a taxa internacional de juros, na forma direta e na forma quadrática, e a dummy para a liberalização de controles sobre o fluxo de capitais demonstraram ser significativas ao nível de confiança de $99 \%$, a taxa fixa de câmbio ao nível de $95 \%$ e o produto interno bruto, as reservas internacionais, a taxa real de câmbio e o nível externo de preços não foram significativos ao nível de $90 \%$. A estatística teste da razão de máxima verossimilhança alcançou 0,41 para nove graus de liberdade, indicando que as estimativas dos parâmetros são conjuntamente diferentes de zero ao nível de confiança de 99\%, enquanto o coeficiente de determinação de McFadden atingiu 0,33 (Tabela 3). 
Tabela 3 - Parâmetros estimados das equações de ocorrência de crises cambiais e ataques especulativos para o Brasil

\begin{tabular}{|c|c|c|}
\hline Variáveis explicativas & Com balança comercial & Sem balança comercial \\
\hline Oferta de moeda (M1) & $\begin{array}{r}10,39 \\
* * *(3,29)\end{array}$ & $\begin{array}{r}9,25 \\
* * *(2,88)\end{array}$ \\
\hline Reservas Internacionais & $\begin{array}{r}-2,73 \\
(-1,24)\end{array}$ & $\begin{array}{r}-1,27 \\
(-0,55)\end{array}$ \\
\hline Taxa real efetiva de câmbio & $\begin{array}{r}3,88 \\
(1,39)\end{array}$ & $\begin{array}{r}5,16 \\
*(1,83)\end{array}$ \\
\hline Produto Interno Bruto real & $\begin{array}{r}-4,55 \\
(-0,79)\end{array}$ & $\begin{array}{r}-8,16 \\
(-1,34)\end{array}$ \\
\hline Taxa de câmbio fixa & $\begin{array}{r}-5,01 \\
* *(-2,20)\end{array}$ & $\begin{array}{r}-5,58 \\
* * *(-2,50)\end{array}$ \\
\hline Taxa internacional de juros & $\begin{array}{r}22,48 \\
* * *(2,51)\end{array}$ & $\begin{array}{r}23,78 \\
* * *(2,64)\end{array}$ \\
\hline Taxa internacional de juros (forma quadrática) & $\begin{array}{r}-10,12 \\
* * *(-2,52)\end{array}$ & $\begin{array}{r}-10,74 \\
* * *(-2,65)\end{array}$ \\
\hline Nivel externo de preços & $\begin{array}{l}-11,69 \\
(-1,54)\end{array}$ & $\begin{array}{r}-14,4 \\
* *(-1,99)\end{array}$ \\
\hline Dummy para controles de capital & $\begin{array}{r}3,57 \\
* * *(2,68)\end{array}$ & $\begin{array}{r}3,33 \\
* * *(2,51)\end{array}$ \\
\hline Saldo da balança comercial & & $\begin{array}{r}-3,99 \\
* *(-1,94)\end{array}$ \\
\hline Constante & $\begin{array}{r}1,31 \\
(0,14) \\
\end{array}$ & $\begin{array}{r}5,5 \\
(0,58) \\
\end{array}$ \\
\hline Estatística teste da razão de máxima verossimilhança & 0,41 & 0,45 \\
\hline Coeficiente de determinação $\left(R^{2}\right)$ & 0,33 & 0,36 \\
\hline
\end{tabular}

Fonte: elaboração própria.

Observação: O modelo estatístico utilizado foi o Probit. O espaço amostral compreendeu 204 observações. Os números entre parênteses indicam as estatística "t". Os sinais * ${ }^{* *},{ }^{* * *}$ denotam que a variável em questão é significativa aos níveis de confiança de $99 \%, 95 \%, 90 \%$, respectivamente.

Na versão do modelo OP com o saldo da balança comercial, cinco variáveis demonstraram ser significativas ao nível de confiança de 99\%: a oferta de moeda nacional, a taxa de câmbio fixada pelo governo, a taxa internacional de juros na forma direta e na forma quadrática e a dummy para a liberalização de controles sobre o fluxo de capitais; duas ao nível de confiança de 95\%: o saldo da balança comercial e o nível externo de preços; e duas não foram significativas ao nível de confiança de 90\%: o produto interno bruto e as reservas internacionais. A estatística teste da razão de máxima verossimilhança alcançou 0,45 para dez graus de liberdade, indicando que as estimativas dos parâmetros são conjuntamente diferentes de zero ao nível de confiança de $99 \%$, enquanto o coeficiente de determinação de McFadden atingiu 0,36 (Tabela 3).

As estimativas dos parâmetros das duas versões do modelo OP, bem como as respectivas estatísticas t, são apresentadas na Tabela 3. Nessa tabela constam também as estatísticas-teste das razões de máxima verossimilhança e os coeficientes de determinação de cada regressão.

O parâmetro estimado do saldo da balança comercial apresentou sinal conforme previsto pelo modelo de Krugman (1979) e foi significativo ao nível de confiança de 95\%. A introdução dessa variável na regressão elevou o nível de confiança das estimativas dos parâmetros da taxa real efetiva de câmbio, da taxa de câmbio fixada pelo governo e do nível externo de preços. Essa mudança sugere que parte do efeito da taxa real efetiva de câmbio sobre a probabilidade de ocorrência de crises cambiais e ataques especulativos aconteça por intermédio do saldo da balança comercial (Tabela 3). 
A variável dummy introduzida para captar o efeito da liberalização dos controles sobre o fluxo de capitais externos foi significativa ao nível de confiança de $99 \%$ nas duas versões da regressão. O sinal dessa variável foi positivo, indicando que a liberalização dos controles sobre o fluxo de capitais esteve diretamente relacionada com o aumento da probabilidade de ocorrência de ataques especulativos e crises cambiais no período seguinte (Tabela 3). Este resultado está em consonância com estudos recentes que têm atribuído o aumento da quantidade e da intensidade das crises cambiais à liberalização dos fluxos de capitais observada em muitos países em desenvolvimento a partir do final da década de oitenta. (Calvo e Mendoza, 1996; Wyplosz, 1998; e Fundo Monetário Internacional, 1998).

Os parâmetros estimados nas regressões foram utilizados para calcular as probabilidades estimadas de crises cambiais e ataques especulativos no período seguinte. Essas probabilidades são apresentadas nos Gráficos 1 e 2. Verificou-se que as probabilidades estimadas das regressões atingiram máximos locais nos períodos que antecederam as crises cambiais e os ataques especulativos no Brasil entre janeiro de 1982 e janeiro de 1999.

As probabilidades estimadas de ocorrência de crises cambiais e ataques especulativos nos meses que precederam esses eventos estão na Tabela 4, que apresenta também a média das probabilidades estimadas nos períodos em que esses eventos não ocorreram. O modelo OP produziu maiores probabilidades estimadas para as crises cambiais e ataques especulativos ocorridos nos anos oitenta, comparativamente àqueles ocorridos nos anos noventa. Tal resultado oferece respaldo à conclusão de Andrade e Divino (1999, p. 26) de que os fundamentos macroeconômicos foram mais importantes nas crises ocorridas nos anos oitenta que naquelas ocorridas nos anos noventa.

Gráfico 1 - Probabilidade estimada de ocorrência de crises cambiais no Brasil. Modelo sem balança comercial

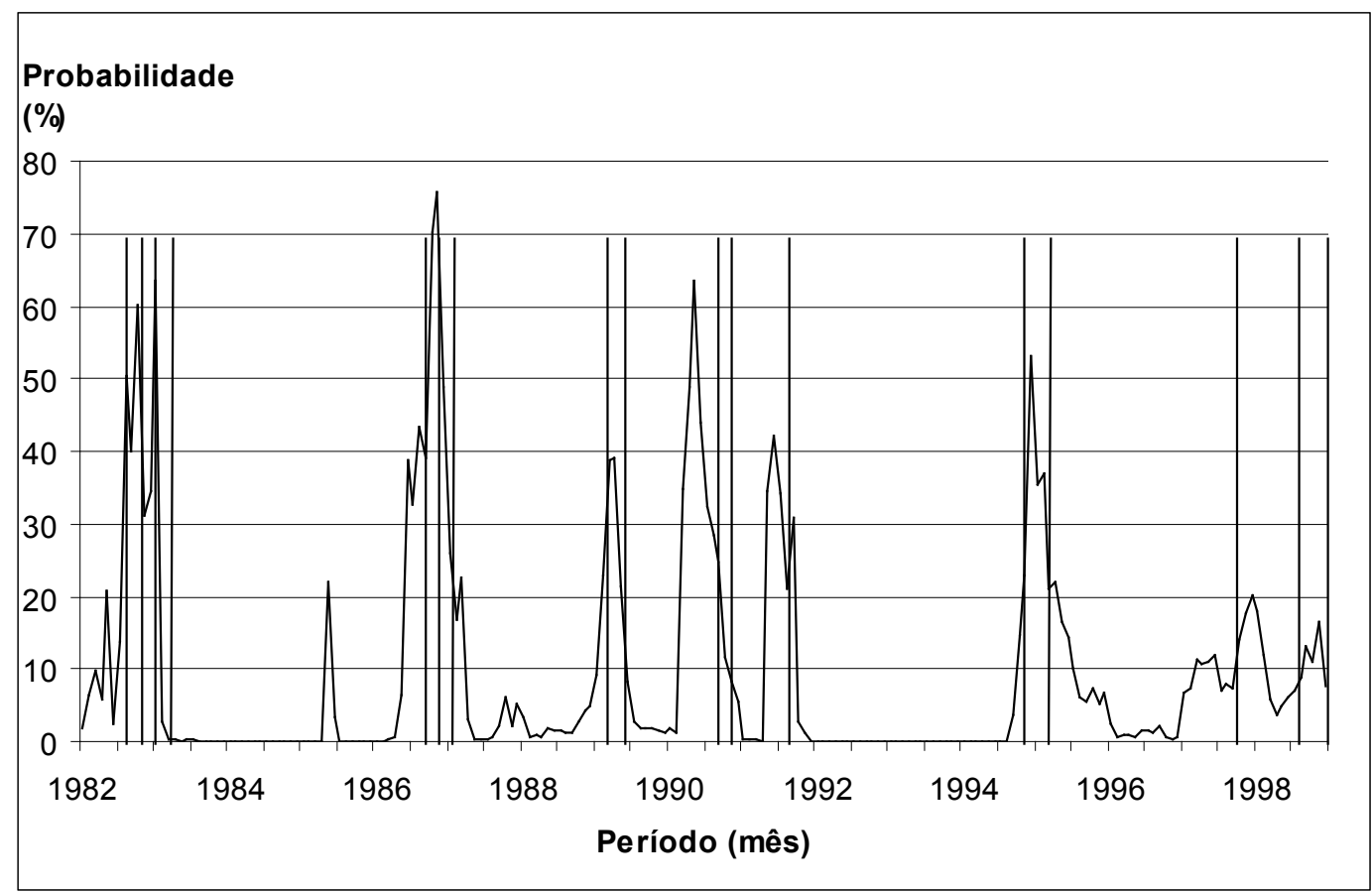


Gráfico 2 - Probabilidade estimada de ocorrência de crises cambiais no Brasil. Modelo com balança comercial

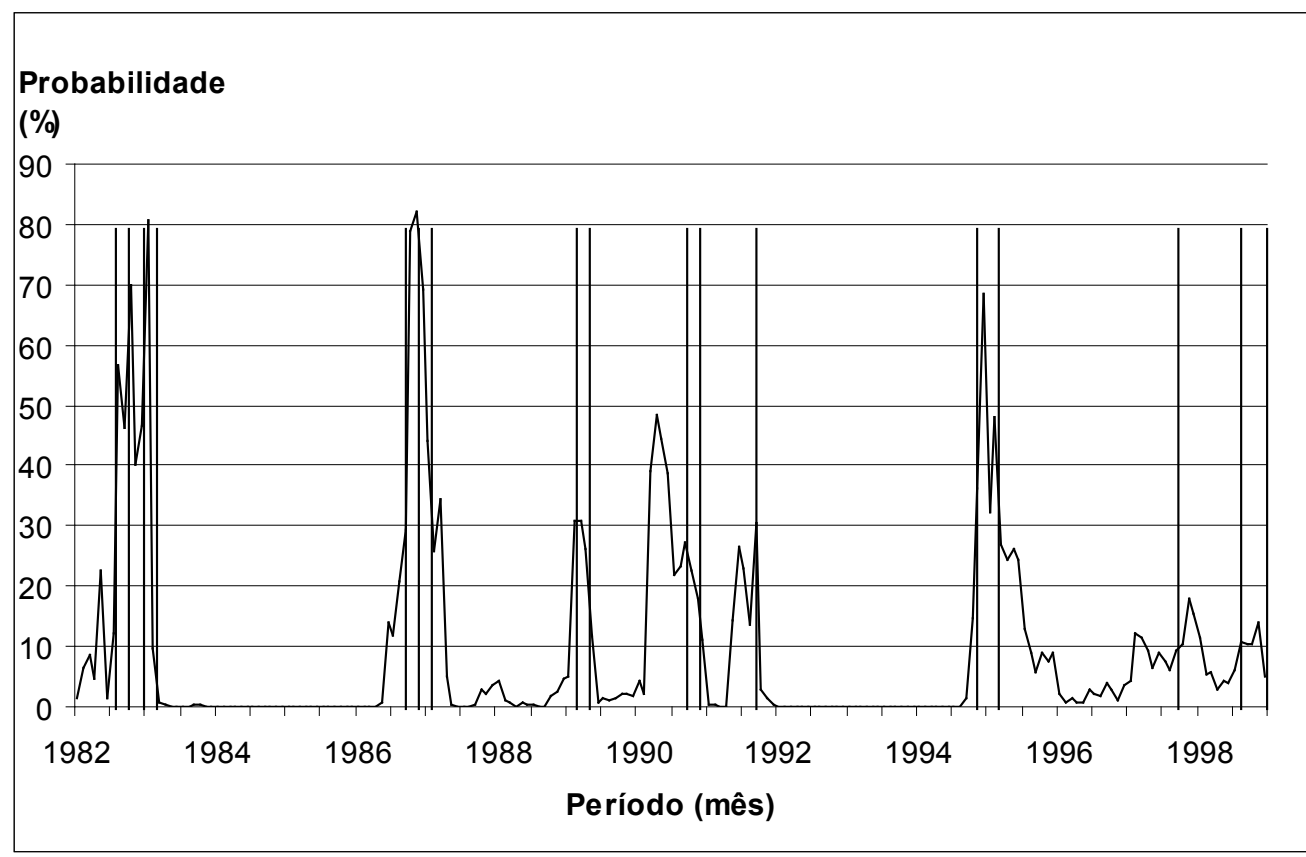

Tabela 4 - Estimativas das probabilidades de ocorrência de ataques especulativos e crises cambiais nos meses em que eles ocorreram

\begin{tabular}{|c|c|c|}
\hline Período & Sem balança comercial & Com balança comercial \\
\hline set/82 & 50,4 & 56,8 \\
\hline out/82 & 39,9 & 46,1 \\
\hline $\mathrm{jan} / 83$ & 34,6 & 46,7 \\
\hline $\mathrm{fev} / 83$ & 63,5 & 80,7 \\
\hline out $/ 86$ & 39,1 & 29,5 \\
\hline $\mathrm{dez} / 86$ & 75,7 & 82,2 \\
\hline jan/87 & 48,8 & 69,2 \\
\hline $\mathrm{fev} / 87$ & 26,0 & 44,2 \\
\hline$a b r / 89$ & 38,6 & 30,8 \\
\hline mai/89 & 39,2 & 26,1 \\
\hline jun/89 & 21,4 & 11,7 \\
\hline out $/ 90$ & 24,7 & 27,4 \\
\hline nov/90 & 11,7 & 22,7 \\
\hline set/91 & 21,0 & 13,7 \\
\hline out $/ 91$ & 30,9 & 30,6 \\
\hline $\mathrm{dez} / 94$ & 22,9 & 36,2 \\
\hline mar/95 & 37,0 & 48,0 \\
\hline out $/ 97$ & 7,3 & 9,5 \\
\hline set/98 & 8,9 & 10,6 \\
\hline jan/99 & 7,7 & 5,2 \\
\hline Média & 32,5 & 36,4 \\
\hline Média alterna $^{1}$ & 7,2 & 6,8 \\
\hline
\end{tabular}

\footnotetext{
${ }^{1}$ Média dos demais períodos.
}

Fonte: elaboração própria. 
As probabilidades médias nos meses que precederam crises cambiais ou ataques especulativos, 32,5\% na regressão sem balança comercial e 36,4\% na regressão com balança comercial, foram sensivelmente superiores àquelas nos meses que não precederam aqueles eventos, 7,2\% e 6,8\%, respectivamente (Tabela 4 ).

Probabilidades de ocorrência de crises cambiais e ataques especulativos elevadas também foram observadas em períodos que, apesar de não imediatamente precedentes a crises cambiais ou ataques especulativos, foram seguidos desses eventos com defasagens de dois a cinco meses. Nesta circunstância estão os meses de novembro e dezembro de 1982, novembro de 1986, maio a julho de 1990 e janeiro de 1995. Apesar de não precederem, imediatamente, crises cambiais e ataques especulativos, esses períodos foram seguidos, com três ou quatro meses de defasagem, por eventos dessa natureza. Assim, verificou-se que a equação estimada do modelo OP é capaz de identificar a iminência de crises cambiais e ataques especulativos com antecedência superior à de um mês. Esta conclusão é amparada pelo exame dos coeficientes de determinação produzidos pelas regressões da ocorrência de crises cambiais e ataques especulativos contra as variáveis explicativas antecipadas em dois ou mais meses, apresentados na Tabela 5.

Tabela 5 - Coeficientes de determinação das regressões variando a antecedência dos regressores em relação à ocorrência da crise cambial

\begin{tabular}{ccc}
\hline Antecedência dos regressores & Sem balança comercial & Com balança comercial \\
\hline 1 & 32,8 & 37,3 \\
2 & 35,3 & 35,3 \\
3 & 31,3 & 32,1 \\
4 & 27,6 & 30,0 \\
5 & 15,7 & 27,2 \\
\hline
\end{tabular}

Fonte: elaboração própria.

As regressões do modelo OP produziram coeficientes de determinação superiores a $30 \%$ com até três meses de antecedência em relação ao mês de ocorrência da crise cambial ou ataque especulativo (Tabela 5). Nesse caso, aumenta a possibilidade de antecipação de ataques especulativos por parte do governo, conferindo-lhe maior capacidade de adoção de medidas preventivas.

\section{CONCLUSÃO}

O objetivo deste estudo foi investigar os determinantes das crises cambiais e ataques especulativos no contexto brasileiro. Mais especificamente, objetivou-se estimar os parâmetros da equação de probabilidade de ocorrência de ataques especulativos no Brasil, tal como concebida no modelo de Ötker e Pazarbasioglu (1995).

Os resultados estatísticos indicaram a não rejeição da hipótese de que o modelo de Ötker e Pazarbasioglu (1995) explica, em alguma medida, a ocorrência de crises cambiais e ataques especulativos no Brasil, no período de janeiro de 1982 a janeiro de 1999. Os parâmetros estimados das variáveis explicativas apresentaram, sem exceção, sinais conforme os previstos pelo modelo.

O saldo da balança comercial, introduzido no conjunto de variáveis explicativas, demonstrou ser significativo, com o sinal previsto pelo modelo de Krugman (1979), e contribuiu para o aumento do poder explicativo do modelo. A variável dummy introduzida para verificar o efeito da liberalização de controles do fluxo de capitais sobre a probabilidade de ocorrência de crises cambiais e ataques especulativos indicou relação positiva e significativa entre essa variável exógena e a endógena. 
As probabilidades estimadas foram capazes de indicar a iminência de crises cambiais e ataques especulativos com até três meses de antecedência, demonstrando utilidade potencial como sinal antecedente que permita a adoção de medidas preventivas.

\section{REFERÊNCIAS BIBLIOGRÁFICAS}

Agénor, Pierre-Richard; Hoffmaister, Alexander W.; Medeiros, Carlos I. Cyclical fluctuations in Brazil's real exchange rate: the role of domestic and external factors. IMF Working Paper ${ }^{\circ}$ 97/128. Washington: Fundo Monetário Internacional, 1997.

Agénor, Pierre-Richard; Bhandari, Jagdeep S.; Flood, Robert P. Speculative attacks and models of balance-of-payments crises. IMF Staff Papers, v. 39, n. 2, p. 357-94. Washington: Fundo Monetário Internacional, 1992.

Andrade, Joaquim Pinto de; Divino, José Ângelo. The role of the fundamentals and the rumors. Texto para Discussão da Série NECEMA 02/99. Brasília: Universidade de Brasília/Departamento de Economia, 1999.

Aurélio, Marcela Meirelles; Silva, Marcos Eugênio da. Crise cambial e intervenções em mercados de derivativos de câmbio. São Paulo: Fundação Instituto de Pesquisas Econômicas, Economia Aplicada, v. 3, n. 4, p. 519-536, out./dez. 1999.

Banco Central do Brasil. Relatório anual, vários anos. Brasília: Banco Central do Brasil.

Blanco, Hermínio; Garber, Peter M. Recurrent devaluation and speculative attacks on the Mexican peso. Journal of Political Economy 94, p. 148-66, February 1986.

Bonomo, Marco; Terra, Cristina. The political economy of exchange rate policy in Brazil: 1964-1997. Rio de Janeiro: Fundação Getúlio Vargas, EPGE - Ensaios Econômicos n. 341, 1999.

Burnside, Craig; Eichenbaum, Martin; Rebel, Sérgio. On the fundamentals of self-fulfilling speculative attacks. NBER Working Paper $n^{\circ}$ 6758. Cambridge: National Bureau of Economic Research, 2000.

Calvo, Guillermo A.; Mendoza, Enrique G. Mexico's balance-of-payments crisis: a chronicle of a death foretold. Journal of International Economics, v. 41, n. 3-4, p. 235-264, 1996.

. Capital-markets crises and economic collapse in emerging markets: an informational-frictions approach. American Economic Association Papers and Proceedings, v. 90, n. 2, p. 56-64, 2000.

Caramazza, Francesco; Ricci, Luca; Salgado, Ranil. Trade and financial contagion in currency crises. IMF Working Paper n 00/55. Washington: Fundo Monetário Internacional, 2000. 46p.

Cavalari, Lilia; Corsetti, Giancarlo. Shadow rates and multiple equilibria in the theory of currency crises. Journal of International Economics 51, p. 275-286, 2000.

Chang, Roberto; Velasco, Andres. The Asian liquidity crisis. NBER Working Paper $n^{\circ}$ 6796. Cambridge: National Bureau of Economic Research, 1998.

Cole, Harold L.; Kehoe, Timothy J. A self-fulfilling model of Mexico’s 1994-1995 debt crisis. Journal of International Economics, v. 41, n. 3-4, p. 309-330, 1996.

Cumby, Robert E.; van Wijnbergen, Sweder. Financial policy and speculative runs with a crawling peg: Argentina, 1978-1981. Journal of International Economics 27, p. 111-127, 1989.

Eichengreen, Barry; Rose, Andrew K.; Wyplosz, Charles. Exchange market mayhem: the antecedents and aftermath of speculative attacks. Economic Policy 21, p. 249-312, October 1995.

. Contagious currency crises. Disponível em: http: \\heiwww.unige wyplosz, 1997. Acessado em: 22 de abril de 1999.

Flood, Robert P.; Garber, Peter M. Collapsing exchange-rate regimes. Some linear examples. Journal of International Economics 17, p. 1-13, 1984. 
Frankel, Jeffrey A.; Rose, Andrew K. Currency crashes in emerging markets: an empirical treatment. Journal of International Economics, v. 41, n. 3-4, p. 351-366, 1996.

Fritsch, Winston. A crise cambial de 1982-83 no Brasil: origens e respostas. In: Plastino, Carlos Alberto; Bouzas, Roberto (orgs.), A América Latina e a crise internacional. Rio de Janeiro: Edições Graal, 1985.

Fundo Monetário Internacional. World economic outlook. Washington: Fundo Monetário Internacional, May, 1998.

Garber, Peter M.; Svensson, Lars E. O. The operation and collapse of fixed exchange rate regimes. In: Grossman, G.; Rogoff, Kenneth (eds.), Handbook of international economics (v. III). Amsterdan: Elsevier Science B.V., 1995.

Garcia, Márcio G. P.; Valpassos, Marcus Vinícius. Capital flows, capital controls and currency crisis: the case of Brazil in the nineties. Texto para Discussão $n^{\circ}$ 389. Rio de Janeiro: Departamento de Economia da PUC-Rio, 1998.

Goldfajn, Ilan. The swings in capital flows and the Brazilian crisis. Texto para Discussão $n^{\circ} 422$. Rio de Janeiro: Pontifícia Universidade Católica do Rio de Janeiro: Departamento de Economia, 2000. 39p.

Goldberg, Linda S. Predicting exchange rate crises. Mexico revisited. Journal of International Economics 36, p. 413-430, 1994.

Goldfajn, Ilan; Valdés, Rodrigo O. Capital flows and the twin crises: the role of liquidity. IMF Working Paper $n^{\circ}$ 97/87. Washington: Fundo Monetário Internacional, 1997.

Jeanne, Olivier. Are currency crises self-fulfilling? Journal of International Economics 43, p. 263-286, 1997.

Kaminsky, Graciela; Reinhart, Carmen M. On crises, contagion, and confusion. Journal of International Economics, v. 51, n. 1, p. 145-153, 1999.

. The twin crises: the causes of banking and balance-of-payments problems. International Finance Discussion Papers $n^{\circ}$ 544. Washington: Board of Governors of the Federal Reserve System, 1996.

Kaminsky, Graciela; Lizondo, Saul; Reinhart, Carmen M. Leading indicators of currency crises. IMF Staff Papers, v. 45, n. 1. Washington: Fundo Monetário Internacional, 1998.

Krugman, Paul. A model of balance-of-payments crises. Journal of Credit, Money, and Banking, v. 11, n. 3, p. 311-325, 1979.

Masson, Paul. Contagion: monsoonal effects, spillovers, and jumps between multiple equilibria. IMF Working Paper $n^{\circ}$ 98/143. Washington: Fundo Monetário Internacional, 1998.

Melick, William R. Estimation of speculative attack models: Mexico yet again. BIS Working Paper $n^{\circ} 36$. Basiléia: Bank for International Settlements, 1996.

Miranda, Mauro Costa. Crises cambiais e ataques especulativos no Brasil. Trabalhos para Discussão $n^{\circ} 32$. Brasília: Banco Central do Brasil, 2001.

Obstfeld, Maurice; Rogoff, Kenneth. The mirage of fixed exchange rates. Journal of Economic Perspectives, v. 9, n. 4, p. 73-96, 1995.

Ötker, Inci; Pazarbasioglu, Ceyla. Speculative attacks and currency crises: the Mexican experience. IMF Working Paper n95/112. Washington: Fundo Monetário Internacional, 1995.

Pesenti, Paolo; Tille, Cédric. The economics of currency crises and contagion: an introduction. New York: Federal Reserve Bank of New York, FRBNY Economic Policy Review, v. 6, n. 3, p. 3-16, 2000.

Wyplosz, Charles. Speculative attacks and capital mobility. (Versão revisada, em agosto de 1998, de artigo apresentado na Quarta Conferência de Dubrovnik, entre 24 e 26 de junho de 1998. Disponível em: http://heiwww.unige.ch/ wyplosz. Acessado em: 18 de abril de 1999. 